\title{
AS CERVEJARIAS DE IMIGRANTES ALEMÃES E TEUTOS-BRASILEIROS E OS DIVERTIMENTOS CITADINOS
}

\author{
Recebido em: 30/04/2018 \\ Aceito em: 15/10/2018 \\ Jakeline Duque de Moraes Lisboa \\ Prefeitura Municipal de Juiz de Fora \\ Juiz de Fora - MG - Brasil
}

\begin{abstract}
RESUMO: As cervejarias fundadas em Juiz de Fora/MG por imigrantes alemães e teuto-brasileiros nas décadas finais do século XIX foram importantes para a criação de um cenário de divertimento citadino. Através da oferta de diferentes atividades em seus parques de recreio, bosque ou jardins como eram denominados, foi gerado um novo dinamismo social e cultural, haja vista que se localizavam em diversos bairros, descentralizado assim as oportunidades de divertimento. Poucos são os trabalhos que se debruçaram a analisar o lazer sob a perspectiva histórica na cidade mineira e neste sentido propomos compreender parte da história destas cervejarias, num total de nove, e principalmente, o divertimento oferecido e usufruído nestes espaços nas décadas finais do século XIX e a primeiras décadas do século XX. Foi possível perceber que os divertimentos oferecidos nas cervejarias promoveram a sociabilidade urbana local levando a diferentes pontos da cidade, práticas de diversão. Da mesma forma, através das diversas atividades oportunizadas em seus parques, impulsionaram um dinamismo cultural à cidade que já no início do século XX se destacava por sua expressividade industrial e desenvolvimento cultural.
\end{abstract}

PALAVRAS CHAVE: Indústria Cervejeira. Emigrantes e Imigrantes. Divertimento. Atividades de Lazer.

\section{THE BEERS OF GERMAN AND TEUTOS-BRAZILIAN IMMIGRANTS AND CITADINAL FUN}

ABSTRACT: Breweries founded in Juiz de Fora / MG by German and BrazilianBrazilian immigrants in the final decades of the 19th century were important for the creation of a city entertainment scene. Through the offer of different activities in their playgrounds, woods or gardens as they were called, a new social and cultural dynamism was generated, since they were located in several neighborhoods, thus decentralized the opportunities for fun. Few are the works that have analyzed the leisure from the historical perspective in the city of Minas Gerais and in this sense we propose to understand part of the history of these breweries, in a total of nine, and mainly, the fun offered and enjoyed in these spaces in the final decades of century XIX and the first decades of the twentieth century. It was possible to perceive that the amusements offered in the breweries promoted the local urban sociability leading to different points of the city, practices of amusement. In the same way, through the various activities 
opportunized in their parks, they drove a cultural dynamism to the city that already in the early twentieth century stood out for its industrial expressiveness and cultural development.

KEYWORDS: Brewery. Emigrants and Immigrants. Entertainments. Leisure Activities.

\section{Introdução}

Juiz de Fora, cidade mineira localizada na Zona da Mata, recebeu nos anos de 1856 e 1858 imigrantes alemães vindos de diversas regiões da Europa, entre elas, Prússia, Hessen, Tirol, Holstein, Baden, Baviera, Hanover, Pomerânia, Wurttemberg, Saxônia e Nassau. O primeiro grupo de alemães chegou à região em 1856, com o objetivo de trabalhar na construção da estrada União e Indústria, contratado pela companhia de mesmo nome, dirigida pelo engenheiro Mariano Procópio Ferreira Lage, idealizador e responsável pela obra. Já o segundo, estabelecido em 1858, teve como propósito a formação da Colônia D. Pedro II, que visava o abastecimento agrícola do mercado interno. (STEHLING, 1979; CASTRO,1987).

Não existe um consenso sobre o número de imigrantes que chegaram para constituir a Colônia D. Pedro II, conforme dados apontados por Lisboa (2010):

Luiz José Stehling (1979), um dos grandes estudiosos da imigração alemã na cidade, defende a hipótese de que chegaram na cidade 1.162 colonos. De acordo com um levantamento realizado no Porto de Hamburgo por Manfred Lewalter, em 2007, no ano de 1858 saíram da Alemanha com destino ao Brasil 3.378 imigrantes, sendo 1.188 colonos (número obtido com o somatório dos colonos das cinco barcas) que aportaram no Rio de Janeiro com destino a Juiz de Fora. Há ainda o registro de um "recenseamento" do ano de 1887 que se encontra nos arquivos da Igreja de Confissão Luterana de Juiz de Fora, que contém os nomes de 1.190 colonos alemães. (LISBOA, 2010, p.46) 
Em uma dimensão mais ampla, percebe-se que as condições encontradas pelos imigrantes na chegada ${ }^{1}$ ao Brasil não foram aquelas apresentadas pelos agentes de emigração na Alemanha, tendo o grupo enfrentado dificuldades desde sua saída da Europa. Por exemplo, o transporte não era adequado para o número de pessoas a bordo nos navios, e os contratos de trabalho não condiziam com os apresentados pelos agentes. (STEHLING, 1979; ARANTES, 2000; DIEGUES JUNIOR, 1964). Instalados em terras americanas, tiveram que, primeiramente, se organizar tanto economicamente quanto politicamente, para prover sua subsistência e, após alguns anos, já melhor estabelecidos, criaram diversos espaços associativos e oportunizaram diferentes divertimentos. (LISBOA, 2017)

Em Juiz de Fora, a permanência de grupos de imigrantes na cidade, em regiões centrais, não ocorreu de forma diferente, e alguns deles foram protagonistas de diversos empreendimentos industriais, como malharias, curtumes, mecânicas, tipografias, entre outros. Apropriaram-se também da prática associativa como forma de manutenção de seus laços sociais e culturais com a Alemanha.

Assim, em 1872, fundaram as associações mutualistas, como a DeutscherKranken-Unterstützungs-Verein (Sociedade Alemã de Beneficência) e a Sociedade de Beneficência Brasileira-Alemã, em 1894;no âmbito religioso trouxeram a religião luterana, através da Igreja Evangélica de Confissão Luterana, e criaram outras sociedades religiosas, como a Frauenvereine, em 1909- hoje com o nome de Ordem

\footnotetext{
${ }^{1}$ De acordo com Basto (1970) e Quitzau (2011), a imigração alemã no Brasil ocorreu a partir do ano de 1818, quando se instalou o primeiro núcleo agrícola, a Colônia Leopoldina, no sul do estado da Bahia. Quatro anos depois, no mesmo estado, fundou-se a Colônia Frankental, no Vale do Peruíbe, que recebeu este nome devido a seus povoadores serem naturais da região de Francônia. Um ano depois da formação da Colônia Leopoldina, em 1919, estabeleceu-se o município de Nova Friburgo, Rio de Janeiro, também formado por alemães e suíços. Em diversos estudos, Oberacker Junior (1975), Müller (1984), Seyfert (1994), Rambo (1998) e Santana (2010), entre outros, o ano de 1824 é encontrado como marco de criação da primeira colônia de imigrantes alemães, datada de 25 de julho, em São Leopoldo, estado do Rio Grande do Sul.
} 
Auxiliadora das Senhoras Evangélicas (OASE); na música, formaram bandas, que, conforme Esteves; Lage (1915), já existiam, desde 1861, quando da inauguração da Estrada União e Indústria; criaram escolas étnicas, como a Escola alemã, em 1861; promoveram um dinamismo social e cultural, através dos divertimentos oportunizados e vivenciados nos vários espaços associativos, como os parques das cervejarias e, principalmente, nos clubes.

Propomos com este estudo analisar o divertimento como um elemento importante na constituição de uma sociabilidade urbana pelos alemães e seus descendentes, e que resultariam, posteriormente, no surgimento de iniciativas institucionalizadas, com a criação dos clubes, como foi o caso do Turnerschaft Club Gymnastico, fundado em 1909, e do Kegel Club, fundado em 1919, e que permitiam, assim, a vivência dos costumes e práticas de origem alemã.

Por meio das fontes pesquisadas procuramos compreender parte da história das cervejarias $^{2}$ de imigrantes alemães e teuto-brasileiros de Juiz de Fora/MG e principalmente, o divertimento oferecido e usufruído nestes espaços nas décadas finais do século XIX e a primeiras décadas do século XX.

\section{Método}

Inserido no campo da pesquisa histórica, elegemos para esta pesquisa o recorte temporal que tem como marco inicial as duas últimas décadas do século XIX, momento

2 A princípio as cervejarias eram pequenas fábricas que produziam cerveja em processo de alta fermentação e que posteriormente modificaram para o de baixa fermentação. Para a organização de uma cervejaria, segundo Marques (2014), era necessário investir nos seguintes itens de produção: “[...] um moinho, uma cuba de infusão de cevada e filtragem, uma panela de cozimento, um tabuleiro para refinar o extrato de cevada, tinas, tonéis, peças de engarrafar, um motor, uma bomba d'água e garrafas.” (p.49). Além da produção e da oferta de diferentes divertimentos, funcionaram também como "um elemento de intermediação mercantil e financeiro entre o colono e o centro urbano [...]". (FLORES, 2004, p.97). Geralmente, nas cervejarias afastadas do centro urbano, vendiam-se diversos outros produtos, semelhante ao comércio de mercearias como conhecemos nos dias atuais. 
em que as nove cervejarias pertencentes a imigrantes alemães funcionaram na cidade, finalizando-se na segunda década do XX, mais precisamente no ano de 1919, quando é fundado o Kegel Club Juiz de Fora. As cervejarias identificadas foram: Henrique \& Sebastião; Augusto Kremer \& C.; José Weiss; Poço Rico; Dois Leões; Borboleta; Estrella; Winter e Schubert.

Utilizamos, para tanto, algumas fontes de pesquisa para uma exploração mais aprofundada do tema. Entre elas, os jornais, mas, principalmente, O Pharol ${ }^{3}$ e o Jornal do Commercio; os almanaques de Juiz de Fora, revistas e documentos.

No que se refere ao uso dos termos lazer, divertimento ou diversão, autores na atualidade discutem e defendem o uso de um termo ou outro. Optou-se pela expressão divertimento/diversão em grande parte do trabalho, por ser este o vocábulo utilizado na maior parte do período recortado pela presente análise, encontrado principalmente nos jornais e documentos primários.

Percebe-se, além disso, que o termo "sport" passou a ser utilizado para substituir práticas que então eram reconhecidas como divertimento, numa tentativa de aproximação com o modelo desenvolvido na Europa, mas que, devido as características periféricas do Brasil, acabou por chegar aqui antes do esporte propriamente dito, percebido muitas vezes como um divertimento "útil", uma forma de identificação com o “mundo civilizado europeu”. (MELO, 2015, p.52).

Melo (2011), em alguns de seus trabalhos, tem adotado o termo "diversão", sem abandonar as discussões sobre o lazer, pois, para ele, "esse é um possível arranjo da diversão, não o único, talvez nem mesmo na modernidade”. (MELO, 2011, p.74).

\footnotetext{
3 A busca de informações no jornal $O$ Pharol foi feita através de palavras-chave ,procurando-se por noticias publicadas no período de 1876 a 1933, arquivos estes disponíveis no site da Biblioteca Nacional Digital Brasileira. As palavras utilizadas inicialmente foram 'cervejaria' e 'cerveja'. Feito isto, a procura se deu pelos nomes das próprias cervejarias, pelos proprietários das mesmas e pelos divertimentos em questão.
} 
Complementa o autor que a diversão é um fenômeno histórico como qualquer outro, e os estudos sobre este tema permitem recortes temporais anteriores à modernidade, período este associado ao surgimento do lazer moderno e não necessariamente da diversão.

A palavra lazer neste trabalho é citada para se referir ao mesmo fenômeno, pois conforme afirma Dias (2009, p.29), "a simples existência de um signo linguístico não necessariamente atesta a existência de um fato social”. Inversamente, a sua ausência também não impede sua ocorrência. A articulação entre as palavras e as coisas é um fenômeno bem mais complexo. E ainda acrescenta o autor que, "de outra forma, a ausência da palavra de um determinado contexto não significa que o seu conteúdo também o esteja, ou que a sua aplicação analítica àquela circunstância não seja nunca possível.” (DIAS, 2009, p. 29).

\section{Resultados}

As cervejarias de origem alemã instaladas por imigrantes e seus descendentes no Brasil - e em Juiz de Fora não era diferente -, além da diversidade na produção etílica e, nesta esteira, das mudanças ocorridas ao longo do tempo no processo de fabricação da cerveja, contribuíram para a construção de um ambiente citadino dinâmico. Por meio da oferta de divertimentos, as cervejarias favoreceram o surgimento de espaços comuns de convivência, que vieram ao encontro das expectativas da população de diversas cidades brasileiras na transição do século XIX para as décadas iniciais do século XX.

Esses espaços tornaram a cidade mais viva culturalmente, pois passaram a representar para as pessoas novas formas de desfrutar das emoções, ativa ou passivamente, pelas diversas práticas de diversão que puderam ser ali reunidas, 
contribuindo para formação de uma dinâmica social. Estes tipos de cervejaria possibilitaram a construção de uma forma de sociabilidade, aliando a produção, o consumo e o divertimento em um mesmo local.

Destarte, da segunda metade do século XIX até as primeiras décadas do século XX elas se transformarem em um espaço para além da simples produção de produto não durável (no caso das bebidas), oportunizaram também opções de divertimento para a sociedade da época, modificando, assim, o panorama do lazer citadino.

Neste período de reformas de costumes, o Brasil conhece a expansão do processo de urbanização, o desenvolvimento da industrialização, a abertura do país às vanguardas estéticas do mundo dito civilizado, além de se desenvolver uma retórica do trabalho como benfazejo para o país e sua população, com a conseqüente organização dos trabalhadores (OLIVEIRA, 2011, p.44).

Estes ambientes possibilitaram, contudo, a criação de um novo repertório cultural em locais às vezes deslocados da região central, descentralizando assim os espaços de lazer, tornando-os uma oportunidade de passeio para muitos, ofertando “divertimentos adequados”. Abaixo segue um mapa ${ }^{4}$ de localização das cervejarias. Nota-se que em 1920 apenas estavam em produção as cervejarias Germânia, José Weiss e Dois Leões.

\footnotetext{
${ }^{4}$ Mapa com localização de fábricas divulgada por Andrade (1987).
} 


\section{1- Localização das cervejarias}
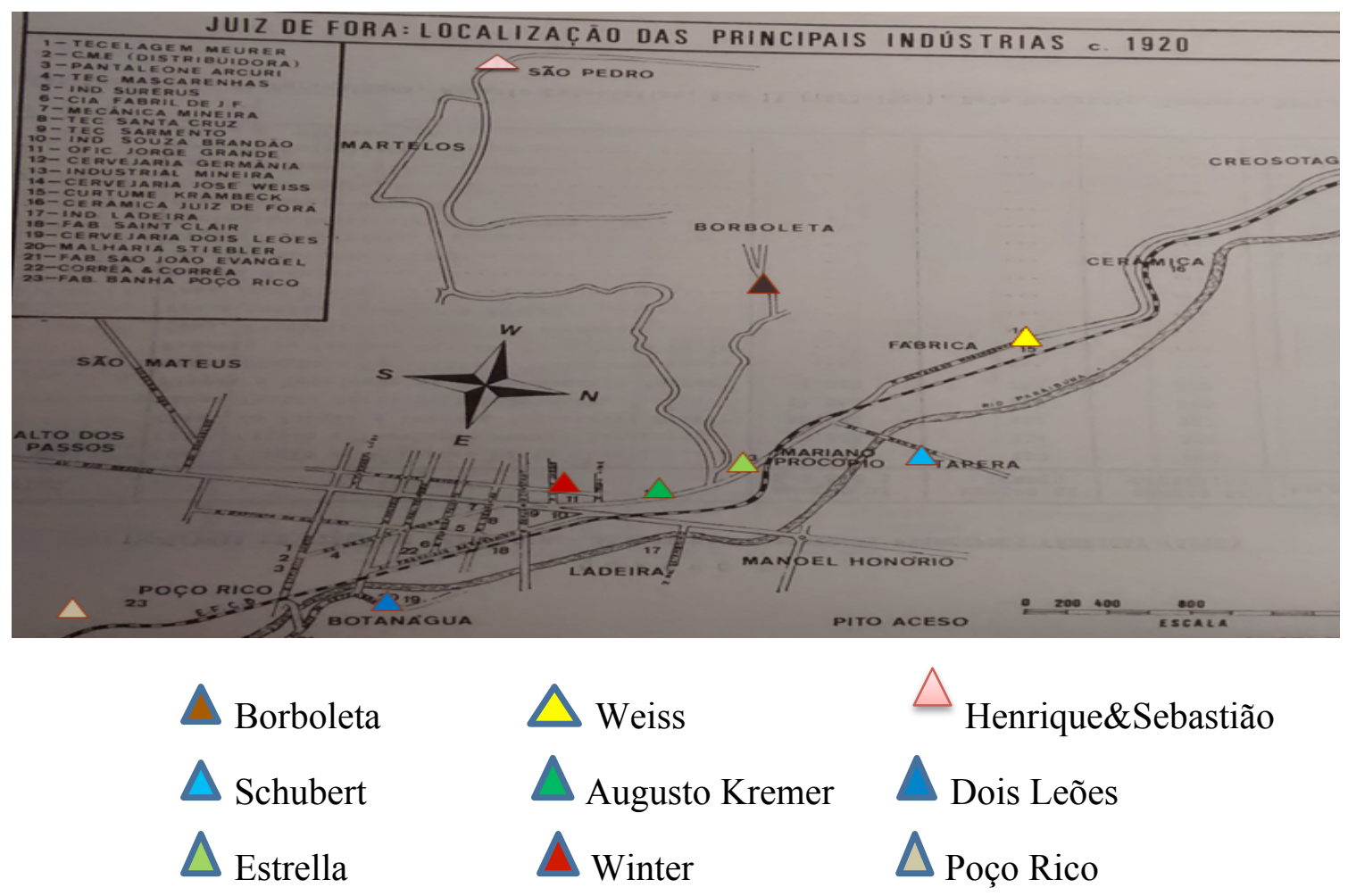

Fonte: Elaborado pela autora

O primeiro registro festivo identificado nas fontes consultadas - e realizado em alguma cervejaria -,foi um baile organizado pelo Club União Luso-Brazileira, na cervejaria José Weiss, datado de 31 de outubro de 1882, tendo se disponibilizado na ocasião até bondes especiais para conduzir os interessados. (O PHAROL, 31/10/1882). Entretanto, observa-se que isso não quer dizer que outras festas não tenham sido organizadas anteriormente, haja vista que a primeira cervejaria foi fundada em 1861 .

Esta foi fundada por Henrique \& Sebastião, ${ }^{5}$ localizando-se no atual bairro São Pedro, onde afirma-se que foi "a primeira indústria que os imigrantes instalaram por conta própria [...].” (STEHLING, 1979). O local fazia parte da Colônia D. Pedro II, que

\footnotetext{
${ }^{5}$ É recorrente na produção historiográfica a respeito desta cervejaria delegar apenas a Sebastião Kunz, toda esta produção etílica, não mencionando seu sócio Henrique Peters. Percebe-se que nestes trabalhos a referência principal é a obra de Luiz José Stehling (1979), a Companhia União e Indústria e os alemães, ou seja, as pesquisas apenas reproduzem a informação sem uma análise mais criteriosa ou empírica.
} 
posteriormente, com a formação dos outros núcleos habitacionais germânicos, ficou conhecida também como Colônia de Cima. (LESSA, 1985, p.75).

Segundo Stehling (1979) foi fundada pelos imigrantes Henrique Peters e Sebastião Kunz e produzia as cervejas conhecidas como barbante, de alta fermentação, ${ }^{6}$ sendo um ponto de referência para os moradores da região que também aproveitavam o espaço, participando dos eventos ali realizados ou simplesmente em reuniões de amigos.

O local era frequentemente referência dos moradores da região para a prática de atividades, principalmente aos finais de semana. Para a construção da capela e do cemitério católico em terreno doado por Sebastião Kunz, foi necessária a realização de eventos de arrecadação de fundos para as obras, com a participação da cervejaria e/ou de seus proprietários, além dos investimentos auferidos pela província sob a rubrica 'obras públicas'.

Capella de S. Pedro, Ex-Colonia D. Pedro II-No dia 30 do corrente, das 10 horas da manhã em diante, terá lugar um leilão das prendas offerecidos para a construção de S. Pedro no lugar denominado Henrique \& Sebastião. Tocará a musica da sociedade allemã. Esperase a concorrencia do publico (O PHAROL, 25 maio 1884, p.2).

Atividades como dança, música, espetáculo com fogos de artifícios, grandes fogueiras e diversos leilões foram oferecidos e prestigiados pelo público presente nestes eventos. A música ficava sob a responsabilidade da banda, composta por moradores da região e regida por João Nepomuceno da Rosa ou, em outras ocasiões, por Henrique Falhauber. Segundo Stehling (1979), estes imigrantes chegaram a formar seis bandas de música, a saber: Banda Tirolesa, da Companhia, Alemã, Faulhaber, São Pedro e

6 "Por não ser pasteurizada, essa cerveja deve ser consumida em poucos dias, porque o líquido no interior da garrafa continua se expandindo, levando à expulsão da rolha ou tampa que veda a garrafa. Como habitualmente, usava-se a rolha amarrada com barbante para selar as garrafas, esse tipo de cerveja ficou conhecido como cerveja barbante". (MARQUES, 2014, p. 37). 
Borboleta. Para ele, alguns colonos que chegaram à cidade em 1858 trouxeram instrumentos musicais, tendo a Companhia União e Indústria, comprado outros que faltavam para as apresentações da banda de música.

Uma das cervejarias mais representativas na cidade, quiçá do estado mineiro, quando se refere ao processo de produção foi a Augusto Kremer \& C., sendo reconhecida também por outras cervejarias do Brasil. Foi fundada em 1867 pela firma Augusto Kremer\& C., sob a direção de Augusto Kremer, filho de Henrique Kremer, que havia adquirido o terreno da Companhia União e Indústria, para montar a filial de sua fábrica de cerveja na cidade, uma vez que já era proprietária de outra na cidade de Petrópolis, no Rio de Janeiro.

Esta foi construída por Henrique Leiden em 1854 e adquirida quatro anos depois por Henrique Kremer. (MELO; KARLS, 2018). Em julho de 1891, houve uma mudança oficial no nome da firma, que passou de Augusto Kremer \& C. para Kremer \& Cia. Em 1906, a Cervejaria passou a ser chamada de Germânia (O PHAROL, 05 maio 1906), mudando para Americana, em 1917, devido a Primeira Guerra Mundial. (O PHAROL, 22 abr.1917).

Da mesma forma que ocorreu com a Cervejaria Sebastião \& Henrique, houve, por parte da Kremer, a oferta de atividades como uma das alternativas paravenda do produto. A Companhia de Ferro-Carril contribuiu para a formação desta cultura de consumo-divertimento nas cervejarias, pois suas linhas de bondes,fosseinicialmente de tração animal ou,mais tarde, movidos a eletricidade,chegavam até o morro da Gratidão, levando os moradores da cidade para a fábrica.

Infelizmente, as fontes não dão indícios de muitos divertimentos ali praticados. Foram identificados, dentre estes, um piquenique realizado no bosque da cervejaria 
pelos sócios do Turnerschaft Club Gymnastico Juiz de Fora, em junho de 1914 (O PHAROL, 20 jun.1914),e um registro de um almoço realizado no bosque, em comemoração à visita do presidente do Estado de Minas Gerais, Antônio Carlos Ribeiro da Andrada, na década de 1920.

Localizada na Colônia D. Pedro II, surgia em 1880 a Cervejaria Borboleta, instalada na Colônia do Meio, ${ }^{7}$ hoje bairro Borboleta, e que tinha como proprietários os irmãos Nicolau e Jacob Scoralick. Devido à localização mais afastada do centro e à dificuldade de acesso para os frequentadores de outros bairros, não teve o mesmo sucesso que outras cervejarias.

Como forma de manter a boa relação com as sociedades de origem alemã e as teuto-brasileiras e reforçar o fator identitário, a fábrica figurava entre os doadores de prendas para a festa de inauguração do estandarte da Sociedade Beneficente BrasileiraAlemã, segundo o jornal $O$ Pharol (06/12/1894). De fato, o costume era comum entre estes tipos de empreendimento, ávidos também por adquirir novos simpatizantes e consumidores. Esta mesma cervejaria era também escolhida por outras sociedades para a arrecadação de dinheiro, por meio do pagamento pelo uso do espaço de diversão: "Realiza-se hoje, na Colônia de Cima, na fabrica de cerveja Borboleta, a segunda kermesse em benefício da Sociedade Allemã de Soccorros Mutuos". (JORNAL DO COMMERCIO, 27/06/1897, p.1).

As fontes não apontam o ano em que surgiu a Cervejaria Estrella. Sabe-se que era localizada no morro da Gratidão, atual Avenida dos Andradas, e pertenceu à família Griese, em especial a Henrique Julios Griese, chefe da família, ficando depois sob a responsabilidade de seu filho, Guilherme Griese.

\footnotetext{
${ }^{7}$ Este nome surgiu com o passar do tempo, pois a localização da cervejaria ainda era confusa neste período, e alguns documentos informavam estar instalada na Colônia de Cima.
} 
Henrique Griese comprou parte de um terreno da Companhia União e Indústria, situada à rua da Gratidão e organizou inicialmente um empório que vendia gêneros do país além de "grande sortimento de sementes de hortaliça chegado directamente da Europa". (JORNAL DO COMMERCIO, 14/03/1897, p.2). Neste mesmo espaço, havia um salão em que eram realizados eventos e festas familiares como o "Grande baile familiar- No salão de Henrique Griese no morro da Gratidão." (O PHAROL, $12 / 05 / 1883)$

A fábrica de cerveja Winter foi fundada em 1888 pelo imigrante Frederico Winter, e noticiada pelo jornal $O$ Pharol da seguinte forma: "Informam-nos que o sr. Frederico Winter pretende estabelecer uma fabrica de cerveja nesta cidade." (O PHAROL, 01/08/1888, p.1). A cervejaria também possuía um espaço utilizado para fins de divertimento e para reuniões, como a que foi realizada pelo Club Gymnastico Riachuelo, "recentemente organizado nesta cidade”. (O PHAROL, 23/02/1890, p.1).

No bairro Tapera, localizado em área suburbana da cidade, nos anos finais da década de 1880, existia uma fábrica de cerveja de propriedade da firma Assis, Bello \& Cia de Produção, também no sistema de alta fermentação, com os devidos cuidados e análise do produto a cargo da inspetoria de higiene do estado. (O PHAROL, 31/10/1889). A firma Tristão, Bello \& Comp. tornou-se responsável pela cervejaria de mesmo nome, com inauguração datada de 5 de abril de 1891, passando a fabricar cervejas de diversas qualidades, como a preta, branca e a dupla, além de água gasosa, produtos comuns em outras cervejarias já citadas.

E para este dia, se anunciava, segundo O Pharol:

[...] o edifício da fabrica e as dependencias da mesma ostentarão vistosa ornamentação, de folhagens e galhardetes, e a excelente banda de musica do Club Democratico Primeiro de Janeiro se fará ouvir, 
espalhando alegria nos corações, que se conservem insensiveis á acção da cerveja (O PHAROL, 05/04/1891, p.1).

Para se chegar à margem esquerda no rio Paraibuna, onde estavam localizada, as pessoas eram transportadas pelos bondes de tração animal (extensão da linha realizada após a inauguração, em 1889, do Hipódromo Ferreira Lage). Os visitantes passeavam no jardim ali existente conhecido como um ponto de diversão, (ALMANAK DE JUIZ DE FORA, 1897) para praticarem também o “jogo da bola”, o tiro ao alvo, velocípedes, além da patinação. Segundo Stehling (1979), aos domingos, o parque da cervejaria era frequentado pela elite juiz-forana "que ali desfilava com sua elegância". (STEHLING, 1979, p.356).

No trajeto até a cervejaria, os bondes foram acompanhados pela banda de música dirigida por Carlos Alves, e no salão principal da fábrica foi servido um copo de cerveja aos convidados, entre os quais, figuras de nome como o Dr. Fernando Torres, Dr. Vaz Pinto, barão de São Marcellino, Comendador Bernardo Halfeld. Nota-se, pelo que fica dito abaixo que, paralelo à manufatura da cerveja, havia necessidade de apresentar aos consumidores um espaço diferenciado, uma verdadeira opção social para a sociedade juiz-forana, que já usufruía de divertimento em regiões habitadas principalmente por imigrantes.

Os proprietários da fabrica de cerveja alli estabelecida estão construindo um parque magnífico, com lagos, cascatas, etc. e pretendem proporcionar aos visitantes velocipedes para corridas, jogo de bolas, apparelhos de gymnastica e mais divertimentos congeneres. Em breve teremos,pois, um optimo ponto de passeios e de passatempos, de que aliás tanto necessitamos, para compensar a monotonia do centro da cidade (O PHAROL, 22/07/1890, p. 2).

Grande parte destas atividades era oferecida pela firma de propriedade de Alfeld \& Preyer, onde havia além do rink de patinação, um botequim que vendia "finísssimas 
bebidas e excellentes mortadella, peixe roast-beef, salada,etc.” (ALMANAK DE JUIZ DE FORA, 1891, p.163).

Nota-se que havia uma cessão de uso do espaço da cervejaria para a firma de alemães Alfeld \& Preyer. Ou seja, mesmo no início das atividades da cervejaria, por mais que a produção e administração tivessem ficado sob a responsabilidade de outros grupos, como os italianos e portugueses, os alemães asseguravam o divertimento naquele "local aprazível", semelhante ao que ocorreu nas outras cervejarias.

A cervejaria mudou novamente de proprietário em 1895, passando agora para as mãos do imigrante alemão Pedro Schubert, que continuou a produzir cerveja e ofertar atividades à sociedade. (ARQUIVO MUNICIPAL DE JUIZ DE FORA, 1895).

Festas também foram realizadas por instituições que iam ao jardim da Tapera aproveitar o espaço ao ar livre, arborizado no evento realizado pela colônia alemã, no dia 2 de setembro, "em commemoração da batalha de Sédan.” (O PHAROL, 1895, p.1). Era um festejo relacionado à história política da Alemanha, já que se tratava de um conflito ocorrido durante a Guerra Franco-Prussiana, sendo este tipo de comemoração comum nas cidades onde os imigrantes alemães se instalavam. Além das festas, o rink de patinação era um investimento em evidência, pois somada à patinação, havia "uma excellente banda de musica italiana", e que tocava também em alguns eventos realizados no local. (JORNAL DO COMMERCIO, 04 ago. 1895, p.2).

Dentro do primeiro núcleo habitacional alemão conhecido como Villagem (localizado afastado do centro da cidade), surgia, em 1879, a Cervejaria José Weiss, pertencente ao imigrante alemão Joseph Weiss, ou José Weiss. Este empresário havia trabalhado na produção de cerveja durante quase oito anos na Fábrica de Augusto Kremer, atuando também como sócio da firma. 
Acredita-se que um dos grandes problemas iniciais que afetaram o crescimento da fábrica foi a dificuldade de acesso, pois os bondes naquele período não chegavam até a Villagem, na Colônia D. Pedro II. Conquanto, a sociedade não deixou de frequentar o estabelecimento que, assim como as outras cervejarias, passou a oferecer diversos divertimentos. O transporte de passageiros surgiria no início da década de 1880, com a utilização de bondes de tração animal, pela Companhia Ferro-Carril ${ }^{8}$, que recebeu autorização tanto do governo provincial quanto da Câmara Municipal para o assentamento dos trilhos. (OLIVEIRA, 1966).

Começaram a partir de 1882 as discussões dentro da Companhia a respeito da necessidade de prolongamento da linha até a fábrica da José Weiss, instalada no subúrbio de Juiz de Fora. A proposta não foi aceita por alguns acionistas, que justificavam o atendimento prioritário para as ruas centrais, finalizando os assentamentos e concluindo a rede na região central, já que a expansão até a Villagem significaria grande dispêndio.

Mesmo com a inexistência de uma linha oficial até a fábrica, circulavam, dependendo dos eventos, bondes especiais colocados pelas entidades organizadoras dos mesmos (O PHAROL, 31/12/1882). Assim sendo, este serviço de transporte, em certos momentos, era viabilizado. A inauguração da linha ocorreu no dia 5 de abril de 1885.

A cervejaria foi palco de prado de corridas, velódromo, espaço para jogo de tênis, prática de críquete, stand de tiro ao alvo e um campo de uso do Tupinambás

\footnotetext{
8 A Companhia Ferro-Carril de propriedade do alemão Felix Schmidt e de Eduardo Batista Roquete Franco ofereceu o primeiro serviço de transporte público urbano de Minas Gerais, atendendo inicialmente as ruas centrais da cidade, como a Imperatriz (atual Marechal Deodoro), Comércio (atual Batista de Oliveira), Espírito Santo, entre outras. (STEHLING, 1979). Posteriormente, com o crescimento da cidade e com a extensão dos bondes até a cervejaria, viu-se a possibilidade de reestruturação viária, pois o bonde se estenderia conforme Oliveira (2001) aos dois extremos: José Weiss e Lamaçal (atualmente bairros Fábrica e Bom Pastor).
} 
Futebol Clube com a realização de diversos campeonatos, principalmente na década de 1920. Portanto, além da atividade de produção da cerveja e do refrigerante se destacava pelo parque e pelo aproveitamento que a sociedade juiz-forana fazia do seu espaço para diversas finalidades, que iam do simples lazer, visitações, às festas, principalmente nos finais de semana, onde acontecia, além destas, apresentações do circo equestre, ${ }^{9}$ o teatro de bonecos, ginástica, boliche, quermesse, tombola, entre outras promoções das entidades. Segundo Lessa (1985), os piqueniques eram animados; dançava-se, embriagava-se e apostava-se em corridas de cavalos; tomava-se a melhor soda da cidade e podia-se patinar ao som de uma orquestra.

Abaixo, o registro da cervejaria em 1885 e um dos seus divertimentos: a roda gigante.

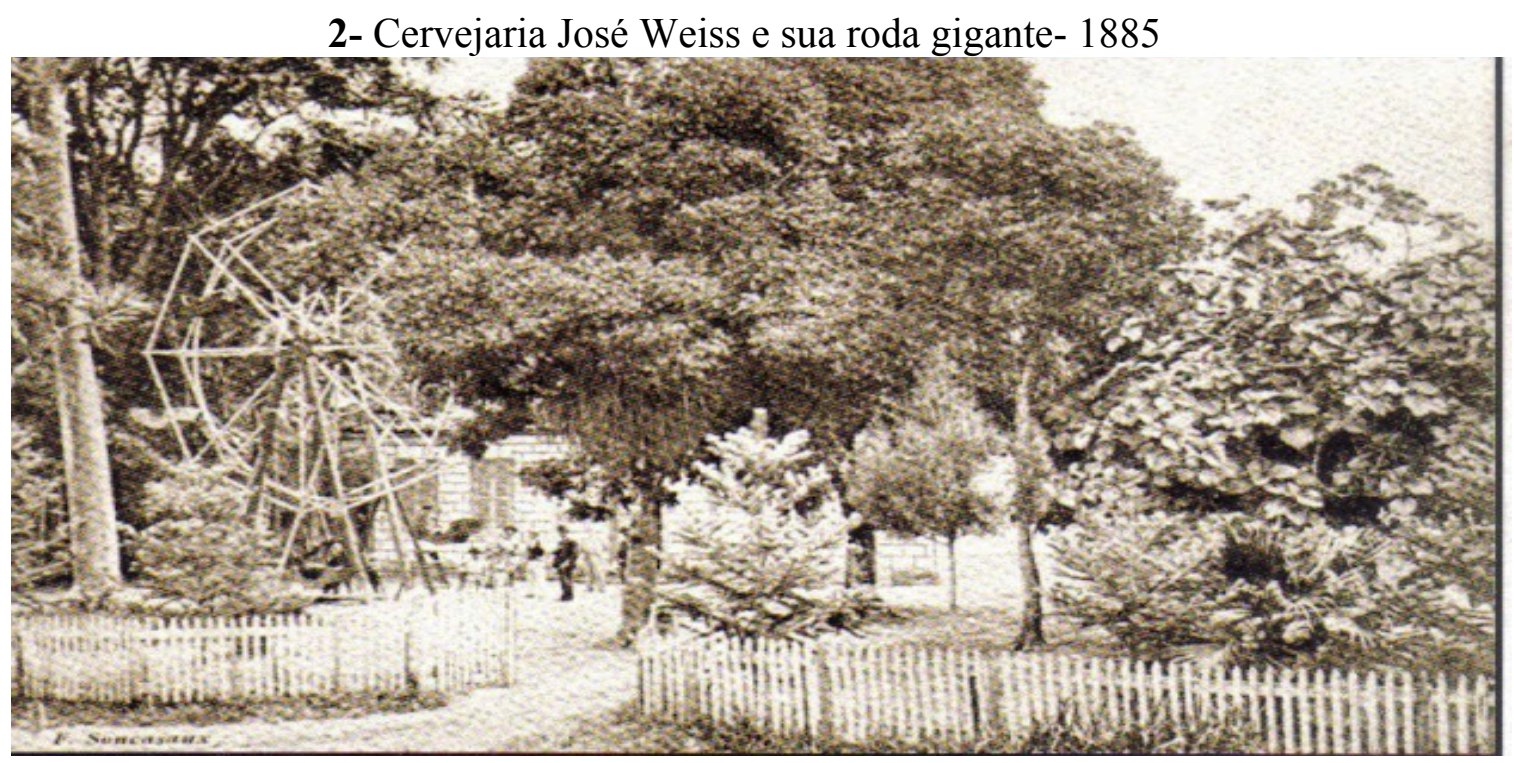

Fonte: STEHLING(1979)

A Fábrica de Cerveja de Freesz \& Irmão era propriedade de Matheus Kascher e dos irmãos Francisco Freesz, Antônio Freesz e João Freesz. (O PHAROL, 29/09/1897).

\footnotetext{
${ }^{9}$ Segundo Silva (2010), os circos de cavalinhos estiveram presentes no século XIX na maior parte das cidades brasileiras, tornando em alguns casos “a única diversão da população local”. (p.128)
} 
Foi fundada em 1881 e situada inicialmente na região central da cidade, no Caminho União e Indústria, hoje atual avenida Getúlio Vargas. (STEHLING, 1979).

Nota-se que assim como aconteceu coma Cervejaria José Weiss, o espaço desta fábrica também se transformou em local de passeio ao ar livre: “C.D. Primeiro de Janeiro- Deve realisar-se amanhã, ás 4 horas da tarde um passeio do socios desse club á fabrica de cerveja Poço Rico. Para a noite de 26 do corrente está marcada uma partida do mesmo club [...].” (O PHAROL, 19/07/1890, p.2).

Carlos Stiebler, foi o responsável pela instalação da fábrica de cerveja alemã, denominada de Dois Leões, situada na margem esquerda do rio Paraibuna ${ }^{10}$, um local ainda pouco povoado se comparado à margem direita, que segundo O Pharol (1906, p.2) era também uma opção de "passeio fora da cidade", sendo instalada na rua Botanágua - que posteriormente ficaria conhecida como avenida Garibaldi-, atual avenida Sete de Setembro.

A identificação da cervejaria com a ideia de passeio também era constante, assim como ocorreu com a Cervejaria José Weiss, pois ficavam em locais afastados do centro da cidade e que, num primeiro momento, não eram atendidos pelos serviços e pelo transporte público de passageiros, o que dificultava o acesso das pessoas às atividades ali oferecidas.

Uma dinâmica social e cultural estava sendo conformada do lado esquerdo do rio Paraibuna, principalmente com a instalação do Parque Stiebler ou Parque de Recreio, espaço este com as mesmas características daqueles encontrados nas demais cervejarias, com objetivos semelhantes e justificados, sobretudo, pela necessidade de venda das cervejas de alta fermentação.

\footnotetext{
${ }^{10}$ A cervejaria Tapera também ficava na margem esquerda do Paraibuna, mas, quando o alemão Pedro Schubert a adquiriu, 1895, ela já havia se estabilizado há alguns anos pelas mãos de outros proprietários.
} 
O parque foi inaugurado em abril de 1903, próximo à fábrica de cerveja. Ali se construiu um prédio destinado ao público, com um grande salão e salas espaçosas para bailes e festas. À frente da casa, foi construído um jardim, e, ao fundo, um parque com caramanchões, "installando no mesmo local jogos athleticos e outros divertimentos", como a casa do "jogo da bola". "Com attractivos taes, o aprazivel bairro Botanagua vae se tornar o ponto obrigatorio dos passeios á tarde, mormente no tempo de verão [...]." (O PHAROL, 21/03/1903, p.2).

O espaço recebeu diversas festas, realizadas também por instituições ligadas ao grupo étnico germânico e divulgadas pelo $O$ PHAROL, como a Escola Alemã (09/07/1903); Sociedade Alemã de Socorros Mútuos (24/04/1904); Turnerschaft Club Gymnastico (01/01/1911) e outros como Club dos Planetas (05/01/1904), Club Gymnastico Força e Coragem (26/09/1906), além de algumas bandas de música que tocavam no parque, geralmente nas tardes de domingo.

Para as festas, havia antecipadamente a divulgação nos jornais, convidando a população, e posteriormente, registrando as notícias sobre os eventos. Era uma forma de destacar a atuação destas instituições na cidade, e afirmar os trabalhos desenvolvidos por elas, bem como a identidade dos imigrantes alemães e descendentes. Em uma das festas realizada pela Escola Alemã no Parque da Cervejaria, o jornal $O$ Pharol, trouxe de forma detalhada a programação e os eventuais acontecimentos:

Festival escolar- Realizou-se hontem no Recreio da cervejaria Stiebler a festa em beneficio da Escola Allemã.

O parque achava-se garridamente ornamentado com bandeiras, escudos, ramagens, etc.

A's (sic) 2 horas da tarde houve sorteio de tombola e em seguida Kermesse.

$\mathrm{A}^{\prime}$ tarde foi soltado um belissimo balão imitação da aeronava $n .9$ de Santos Dumont.

A'noite houve illuminação a giorno, marcha aux flambeauz e demais festejos. 
Tocou a banda de musica Cortez \& Irmãos.

A concorrencia foi numerosa (O PHAROL, 1903, p.2).

Diversos foram os divertimentos realizados no parque da Cervejaria Dois Leões, atraindo determinados grupos de praticantes influenciados também por iniciativas ocorridas no Brasil, e incentivando a criação de instituições esportivas e práticas de diversão, muitas vezes comuns em seus países de origem. Pode-se citar como exemplo a fundação, em 1909, do Turnerschaft Club Gymnastico, no próprio parque da cervejaria, e do Kegel Club, em1919, ambos os clubes de iniciativa dos frequentadores do parque.

3-Alunos do Turnerschaft durante exercícios com bastão na cervejaria - década de 1910

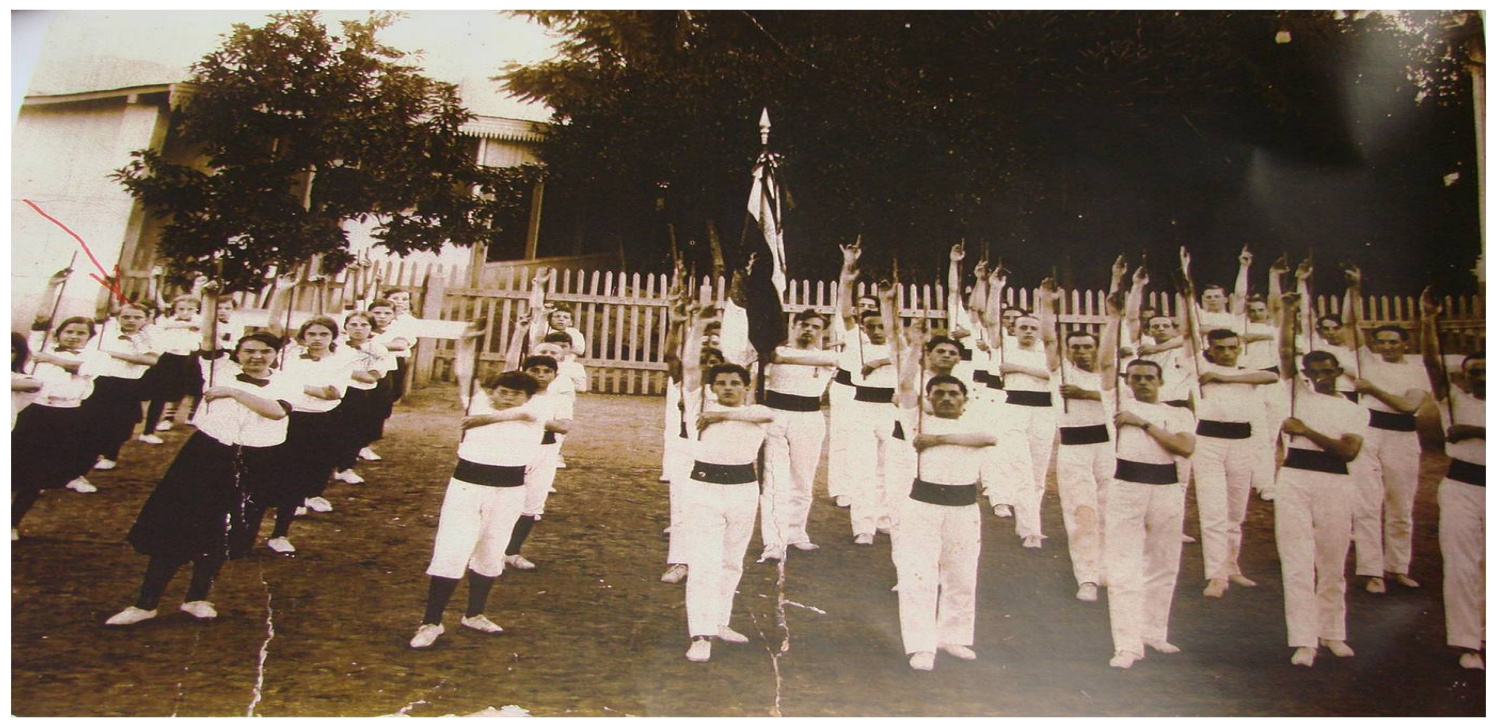

Fonte: LISBOA, 2017.

\section{Discussão}

Juiz de Fora, de modo semelhante ao que ocorreu no Rio de Janeiro, buscou também esta aproximação com os costumes europeus e respirou ares do projeto de civilização de nação brasileira idealizado no período republicano. A urbanização, a nova arquitetura, os novos hábitos dos cariocas teriam atravessado as estradas que ligavam as duas cidades e influenciado diretamente os habitantes de Juiz de Fora. A cidade do Rio 
de Janeiro tornou-se, durante muitos anos, uma caixa de ressonância [...]. (MELO, 2010).

Como cidade do Século XIX, Juiz de Fora não participa da cultura colonial mineira. A proximidade e o maior intercâmbio econômico e cultural com o Rio de Janeiro, assim como a luta política contra o predomínio da zona de Mineração, provocam na cidade um maior cosmopolitismo uma abertura mais acentuada se a compararmos com o antigo centro do ouro (CHRISTO, 1994, p.1).

As mudanças na organização e estruturação de Juiz de Fora, a abertura de ruas, os projetos de saneamento, a efetivação de códigos de postura, a chegada da eletricidade, o aparecimento dos cafés e teatros, principalmente nas décadas finais do século XIX e iniciais do século XX, sugerem uma cidade mais viva, mais "civilizada", moderna, enfim, são sinais de um novo tempo e neste ínterim, os divertimentos realizados nas cervejarias adquirem novos significados, imprimindo na cidade a imagem do espetáculo e dando uma nova configuração do divertimento por intermédio da sociabilidade ali inscrita.

As cervejarias tiveram um importante papel como espaços que proporcionaram divertimento à sociedade juiz-forana, entre as décadas finais do século XIX e as primeiras décadas do século XX. Permitiram o contato do público com diferentes práticas de diversão como as festas, quermesses, piqueniques, tombolas, teatros, músicas, patinação entre outros, em pontos distintos da cidade.

As principais cervejarias que ofereceram estes divertimentos se localizavam em áreas suburbanas, gerando, ao longo do tempo, uma necessidade de transformação urbana com a reestruturação física da mesma. Por exemplo, além da criação de um ambiente que promovesse a sociabilidade da comunidade, era de interesse que 
diferentes segmentos sociais fossem contemplados, exemplificado pelas discussões a respeito da extensão dos bondes para a Cervejaria José Weiss.

Em nota no jornal $O$ Pharol, repugnando a extensão da linha de bondes até a fábrica de José Weiss, escreveu Francisco Antônio Brandi afirmando novamente a conveniência de melhorar os assentamentos para as linhas centrais de bonde, pois beneficiaria o comércio e os negócios da região. O ponto mais curioso da notícia sobre o pedido de prolongamento das linhas até a fábrica, é o fato de Brandi assinalar que o interesse por trás do pedido está relacionado não ao interesse do comércio, mas por razões de divertimento (distração e passeio)e, já enunciando uma das características da fábrica tradicionalmente conhecida: a oferta de lazer à população da cidade. ( $O$ PHAROL, 21/05/1884).

Identifica-se a dualidade existente na aceitação do lazer pela sociedade juizforana. Aqui, outra questão importante pode ser constatada para uma análise histórica do desenvolvimento do lazer local: as mudanças ocorridas na cidade para que a população pudesse usufruir do tempo livre e dos espaços de lazer, assim como as alterações nos sentidos e significados deste 'lazer' a partir das experiências vividas. Ou seja, a cidade muda em função deste novo desfrutar do lazer, e esta prática, por sua vez, acaba por produzir uma nova dinâmica social e econômica na cidade.

Percebemos também uma necessidade de aproximação dos produtos produzidos pelas cervejarias com a população de um modo geral com o esporte que mais alcançava popularidade: o futebol, com a criação de rótulos de cerveja que levavam nomes de times da cidade como o Tupi, Tupinambás, Sport e Renato Dias (O PHAROL, 05/12/1918), como é possivel verificar na figura a seguir 
4- Rótulo da Cervejaria Americana em homenagem ao Tupinambás Futebol Club

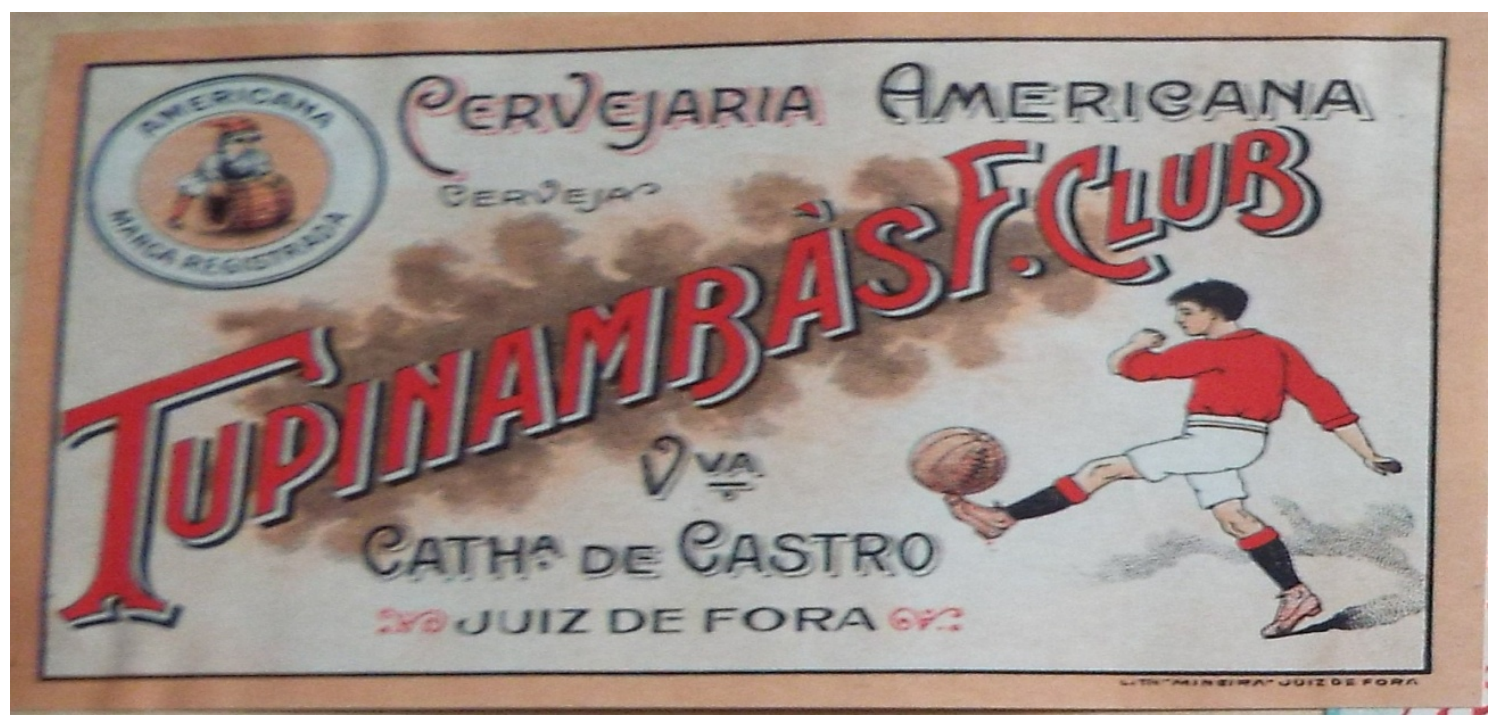

Fonte: ACERVO FUNDAÇÃO MARIANO PROCÓPIO

Seria talvez uma maneira de atingir, com o produto, as camadas mais populares da sociedade, que nem sempre tinham condições financeiras para frequentar o bosque, as festas e os piqueniques. Além disso, essa mesma cervejaria se utilizou do carnaval para organizar estratégias de vendas, produzindo até mesmo poemas, paródias e marchinhas com temas de sua marca, como o exemplo do poema a seguir:

“Cervejaria Germânia!

Não é, senhores, ironia

Affirmar-se em tom profundo

Que a CERVEJARIA GERMANIA

É a primeira do mundo.

Então, a marca Triumpho

Para o calor sempre peças;

Cahindo, jogos e o trumpho

Nunca te sai as avessas.

Ao bebel-a, a gente sonha

E mais dez copos deseja;

Faz engordar; e o Noronha

Só bebe desta cerveja.

A outra marca Germania

Tambem é supimpa; olé!

Faz-nos a Musa espontanea

E o genio melhor, até

A quem não bebe tal marca,

Eu nem lhe tiro o chapéo,

E quando vier a Parca

Não acha o rumo do céo. 
Meu corpo, por isso, almeja, Que ao descer á cova fria, Seja em barril de cerveja, Mas desta CERVEJARIA" (BEGÊ, ? /02/1907, p.2). ${ }^{11}$

\section{Conclusão}

As cervejarias de imigrantes alemães e teuto-brasileiros oportunizaram, por meio de seus parques, jardins e bosques, várias opções de divertimentos, aliados também aos interesses de comercialização do produto, já que, como foi visto, o sistema de alta fermentação exigia que a cerveja fosse consumida rapidamente, sendo as práticas de diversão a estratégia encontrada para seu pronto escoamento, fechando, assim, a relação produção-consumo-divertimento.

Neste cenário do divertimento, proporcionavam à sociedade juiz-forana os espetáculos das corridas de cavalo, bicicleta, tiro ao alvo, ginástica, boliche, teatro, música, dança, entre outras. Interessante que, por se localizarem em pontos diferentes e distantes do centro da cidade, elas expandiram as possibilidades de uso do espaço urbano, incentivando o aparecimento de um novo hábito de locomoção, sendo necessária até mesmo uma nova reestruturação do transporte urbano para atender o público frequentador das cervejarias.

Outro elemento importante em relação às práticas de diversão foi que algumas delas passaram a ser vivenciadas em clubes específicos, principalmente com a fundação do Turnerschaft Club Gymnastico Juiz de Fóra, em 1909, e do Kegel Club Juiz de Fora, em 1919, ambos com a participação de imigrantes alemães e teuto-brasileiros, frequentadores dos parques das cervejarias.

\footnotetext{
${ }^{11}$ O PHAROL, ?, fev. 1907, p. 2.
} 
Foi possível perceber que os divertimentos oferecidos nas cervejarias promoveram a sociabilidade urbana local levando a diferentes pontos da cidade, práticas de diversão. Da mesma forma, por intermédio das diversas atividades oportunizadas em seus parques, impulsionaram um dinamismo cultural à cidade que já no início do século XX se destacava por sua expressividade industrial e desenvolvimento cultural.

\section{REFERÊNCIAS}

ALMANAK DE JUIZ DE FORA, 1891

ALMANAK DE JUIZ DE FORA, 1897.

ANDRADE, S. M. B. V. Classe operária em Juiz de Fora - Uma história de lutas (1912-1924). Juiz de Fora: EDUFJF, 1987.

ARANTES, Luiz Antônio Valle. Caminhos incertos, conflitos religiosos e empreendimentos: a trajetória dos alemães na cidade. In: BORGES, Célia M. (Org.) Solidariedades e Conflitos: Histórias de vida e trajetórias de grupos em Juiz de Fora. Juiz de Fora: Edufjf, 2000.

ARQUIVO MUNICIPAL DE JUIZ DE FORA, 1895.

BASTO, Fernando Lázaro de Barros. Síntese da História da Imigração no Brasil. Rio de Janeiro: [s.n.] 1970.

CASTRO, Newton Barbosa de. A contribuição dos imigrantes alemães na industrialização de Juiz de Fora. In: História Econômica de Juiz de Fora. Juiz de Fora: IHGJF, 1987.

CHRISTO, Maraliz de Castro Vieira. A europa dos pobres: Juiz de Fora na belleèpoque mineira. Juiz de Fora: EDUFJF, 1994

DIAS, Cleber Augusto Gonçalves. Teorias do lazer e modernidade: problemas e definições. Licere, Belo Horizonte, v. 12, n. 2, jun. 2009. Disponível em: https://seer.ufmg.br/index.php/licere/article/view/575 . Acesso em: 12 fev. 2016.

DIEGUES JUNIOR, Manuel. Imigração, Urbanização, Industrialização. Rio de Janeiro: Centro Brasileiro de Pesquisas Educacionais, 1964.

ESteVES, A ; LAGE,O. Álbum do Município de Juiz de Fora. Belo Horizonte: Imprensa Oficial, 1915.

FLORES, Hilda Agnes Hubner. História da Imigração Alemã no Rio Grande do Sul. Porto Alegre: EST, 2004. 
JORNAL DO COMMERCIO, 04 ago. 1895.

JORNAL DO COMMERCIO, 14 mar. 1897.

JORNAL DO COMMERCIO, 27 jun. 1897.

LESSA, Jair. História de Juiz de Fora. Juiz de Fora: Esdeva, 1985

LISBOA, Jakeline Duque de Moraes. Turnerschaft: Clube Ginástico de Juiz de Fora (1909-1979). 2010. 248 f. Dissertação (Mestrado em Educação Física). Universidade Federal de Juiz de Fora, Juiz de Fora, 2010.

O Divertimento nos espaços associativos de imigrantes alemães e teutobrasileiros em Juiz de Fora - MG: do último quartel do séc. XIX ao fim da II Guerra Mundial. 2017. 210 f. Tese (Doutorado em Estudos do Lazer). Universidade Federal de Minas Gerais, Belo Horizonte, 2017.

MARQUES, Teresa Cristina de Novaes. A cerveja e a cidade do Rio de Janeiro de 1888 ao início dos anos de 1930. Brasília: Paco Editorial, 2014.

MELO, V.A. O esporte: uma diversão no Rio de Janeiro do século XIX. Revista Brasileira de Estudos do Lazer. Belo Horizonte, v. 2, n. 3, p. 49-66, set./dez. 2015. 196. Disponível em: https://seer.ufmg.br/index.php/rbel/article/view/1869 . Acesso em: 15 mar. 2017.

. Esporte, cidade e modernidade: Rio de Janeiro. In: MELO, A (Org.). Os sports e as cidades brasileiras: transição dos século XIX e XIX. Rio de Janeiro: Apicuri: FAPERJ, 2010.

. O lazer (ou a diversão) e os estudos históricos. In: ISAYAMA, H. F.; SILVA, S. R. da. Estudos do Lazer: um panorama. Rio de Janeiro: Apicuri, 2011.

; KARLS, Thaina Schwan. Novas dinâmicas de lazer: as fábricas de cerveja no Rio de Janeiro do século XIX (1856-1884). Movimento, Porto Alegre, v. 24, n. 1, p. 147-160, 2018.

MULlER, Telmo Lauro. Colônia alemã, 160 anos de história. São Leopoldo: Rotermund, 1984.

OBERACKER JUNIOR, C. H. A contribuição teuta à formação da nação brasileira. Rio de Janeiro: Presença, 1975.

OLIVEIRA, Marcus Aurelio Taborda de. A educação dos sentidos na história: o tempo livre como possibilidade de formação. In: ISAYAMA, H. F.; SILVA, S. R. da. Estudos do Lazer: um panorama. Rio de Janeiro: Apicuri, 2011.

OLIVEIRA, Paulino. História de Juiz de Fora. Juiz de Fora: Dias Cardoso, 1966. Crônicas. Belo Horizonte: BDMG Cultural, 2001. 
O PHAROL, 31 out. 1882.

O PHAROL, 31 dez. 1882.

O PHAROL, 12 maio 1883.

O PHAROL, 21 maio 1884.

O PHAROL, 25 maio 1884.

O PHAROL, 01 ago. 1888.

O PHAROL, 22 jul. 1890.

O PHAROL, 05 abr. 1891.

O PHAROL, 06 dez. 1894.

O PHAROL, 02 set. 1895.

O PHAROL, 23 fev. 1890.

O PHAROL, 19 jul. 1890.

O PHAROL, 09 jul. 1903.

O PHAROL, 23 set. 1906.

O PHAROL, 01 jan. 1911.

O PHAROL, 29 set. 1897.

O PHAROL, 21 mar. 1903.

O PHAROL, 05 maio 1906.

O PHAROL, fev. 1907.

O PHAROL, 20 jun. 1914.

O PHAROL, 22 abr. 1917.

O PHAROL, 05 dez. 1918.

QUITZAU, Evelise Amgarten. A ginástica alemã na cidade de São Paulo: o turnerschaft von 1890 in São Paulo (1890-1938). In: CONGRESO ARGENTINO, 9 y LATINOAMERICANO DE EDUCACIÓN FÍSICA Y CIENCIAS, LA PLATA, 4 2011. Anais... Disponível: https://congresoeducacionfisica.fahce.unlp.edu.ar. Acesso em: 19 nov. 2015. 
RAMBO, Arthur. O associativismo teuto-brasileiro e os primórdios do cooperativismo no Brasil. Perspectiva Econômica, v. 23, n. 62, jul./ dez. 1998.

SANTANA, Nara Maria Carlos de. Colonização alemã no Brasil: uma história de identidade, assimilação e conflito. Dimensões, v. 25, 2010, p. 235-248. Disponível em: file://D:/Documentos/Downloads/DialnetcolonizacaoAlemaNoBrasilUmaHistoriaDeId entidadeAss-3638002\%20(1).pdf. Acesso: 26 jan. 2015.

SEYFERT, Giralda. A identidade teuto-brasileira numa perspectiva histórica. In: MAUCH, C.; VASCONCELLOS, N. Os alemães no sul do Brasil: cultura, etnicidade, história. Canoas: Ulbra, 1994.

SILVA, Erminia. A teatralidade circense no Rio de Janeiro do século XIX. In: MARZANO, A.; MELO, V. A. (Org.). Vida Divertida: histórias do lazer no Rio de Janeiro (1830- 1930). Rio de Janeiro: Apicuri, 2010.

STEHLING, Luiz José. Juiz de Fora, a Companhia União e Indústria e os Alemães. Juiz de Fora: FUNALFA edições, 1979.

\section{Jornais}

O PHAROL, 06/12/1894; 02/09/1895; 23/02/1890; 19/07/1890; 09/07/1903; 26/09/1906; 01/01/1911; 29/09/1897; 21/03/1903; 05/05/1906; __/02/1907; 20/06/1914; 22/04/1917; 05/12/1918.

\section{Arquivos}

ACERVO FUNDAÇÃO MARIANO PROCÓPIO

\section{Endereço da Autora:}

Jakeline Duque de Moraes Lisboa

Secretaria de Educação

Rua Getúlio Vargas, 200. Centro

Juiz de Fora - MG - 36.010-909

Endereço Eletrônico: jaklisboa@yahoo.com.br 